\title{
Mecanismos de resistencia antimicrobiana en patógenos respiratorios
}

\author{
Antimicrobial resistance mechanisms in respiratory pathogens
}

\author{
Claudia Moreno M', Rubén González E², Constanza Beltrán³.
}

\begin{abstract}
RESUMEN
Las infecciones del tracto respiratorio representan la indicación más frecuente de antibióticos en pacientes ambulatorios, lo cual se hace sobre bases empíricas. Una falla clínica al tratamiento puede explicarse por resistencia antimicrobiana, que últimamente ha aumentado en patógenos respiratorios. Los microorganismos desarrollan nuevos mecanismos de resistencia antibiótica y comparten virulencia por diversos sistemas. Este fenómeno representa un problema clínico y dificulta el manejo de patologías infecciosas, por lo cual es necesario utilizar nuevas estrategias para el uso adecuado de antimicrobianos. Patógenos respiratorios como S. pneumoniae y S. pyogenes presentan resistencia a betalactámicos por mutaciones en las uniones proteicas a penicilina $(P B P)$ y la resistencia a macrólidos se explica por dos mecanismos: metilación del ribosoma y expulsión del antibiótico por bombas de eflujo; $\mathrm{H}$. influenzae y M. catarrhalis expresan resistencia a betalactámicos debido a hidrólisis enzimática por b-lactamasas.

Palabras clave: Resistencia, antimicrobiana, transferencia horizontal de genes, patógenos, respiratorio.
\end{abstract}

\begin{abstract}
Respiratory tract infections are the most frequent indication of antibiotics in outpatient settings, based on empirical data. Clinical treatment failure can be explained by antimicrobial resistance, which has recently increased in respiratory pathogens. Microorganisms develop new antimicrobial resistance mechanisms and virulence is shared by different systems. This phenomenon represents a clinical problem and hampers the handling of infectious diseases. It is therefore necessary to utilize new strategies for the appropriate use of antimicrobials. Respiratory pathogens such as $S$. pneumoniae and $S$ pyogenes present antimicrobial resistance to beta-lactams by mutations in penicilin binding proteins (PBP); resistance to macrolides is explained by two mechanisms: ribosome methylation and antibiotic export by efflux pumps. $\mathrm{H}$. influenzae and $M$. catarrhalis express beta-lactam resistance due to enzymatic hydrolysis by $b$-lactamases.
\end{abstract}

Key words: Resistance, antimicrobial, horizontal gene transfer, pathogens, respiratory.

\footnotetext{
Médico de Microbiología, Facultad de Medicina, Universidad de Chile.

Médico del Departamento de Otorrinolaringología, Escuela de Medicina, Pontificia Universidad Católica de Chile.

Médico Otorrinolaringólogo, Escuela de Medicina, Pontificia Universidad Católica de Chile.
} 


\section{INTRODUCCIÓN}

Las infecciones del tracto respiratorio son la principal causa de consulta médica a nivel de atención primaria y representan la indicación más frecuente de antibióticos en pacientes ambulatorios, lo cual se hace sobre bases empíricas. Estas infecciones pueden presentar serias complicaciones si son tratadas de manera inefectiva ${ }^{1}$.

La resistencia antimicrobiana ha aumentado en patógenos respiratorios, constituyendo un importante problema para la elección de un antibiótico. Los microorganismos han desarrollado sistemas de resistencia a diversos agentes antimicrobianos ${ }^{2}$. Las bacterias han evolucionado, compartiendo información genética entre ellas. Existen interacciones recíprocas entre las bacterias y el huésped, generando un sistema en homeostasis ${ }^{3}$. Estas poblaciones bacterianas reciben el nombre de microbiota normal (conocida como flora bacteriana) localizada en la cavidad oral, nasofaringe, piel, mucosa intestinal y genitourinaria. La microbiota puede proteger de agentes patógenos ${ }^{4}$. La presencia y desarrollo de estos microorganismos se denomina colonización, sin expresión clínica ni detección de respuesta inmune en el huésped $^{6}$. Estas bacterias pueden producir infec- ción cuando disminuye el sistema inmune, frente a tratamiento inmunomodulador, uso de instrumentos invasivos o por un desbalance de la microbiota en el curso de un tratamiento antibiótico $0^{6}$.

Los microorganismos patógenos poseen genes de virulencia que les da la capacidad de producir daño a un huésped susceptible. La diseminación de esta virulencia entre especies bacterianas mediante transferencia horizontal de genes determina la evolución de patógenos emergentes ${ }^{7}$.

En este nuevo escenario, es relevante conocer los mecanismos principales de resistencia antimicrobiana y las opciones terapéuticas en el caso de los principales patógenos respiratorios.

\section{MECANISMOS DE RESISTENCIA BACTERIANA}

La resistencia antimicrobiana es un problema continuo y en aumento. Se hace aún mayor cuando un microorganismo presenta más de un mecanismo de resistencia y cuando tiene la facultad de transmitirlo, no sólo a su descendencia, sino también a otras bacterias de su misma 0 diferente especie ${ }^{8}$.

Los fenómenos de resistencia antimicrobiana son variados, destacando entre ellos cuatro mecanismos principales (Figura 1):

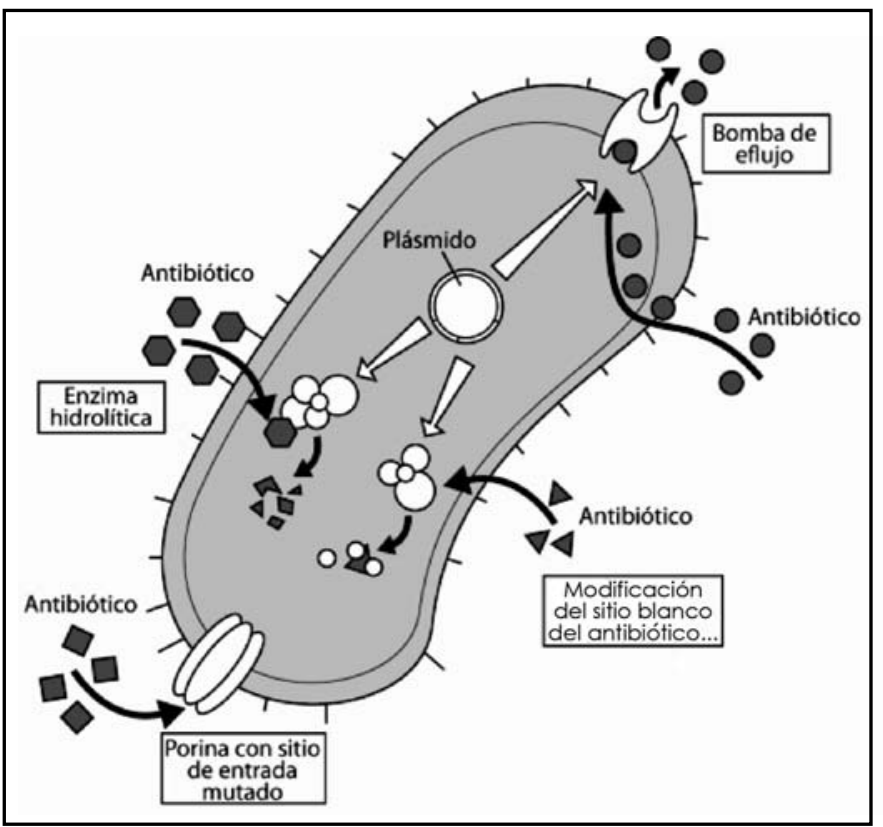

Figura 1. Mecanismos de resistencia antimicrobiana. 


\section{1) Enzimas hidrolíticas}

Las bacterias sintetizan enzimas que hidrolizan al antimicrobiano, destruyendo su acción antibacteriana, sin tener posibilidad de actuar sobre el microorganismo.

- Beta-lactamasas: son enzimas que hidrolizan la unión peptídica endocíclica del anillo betalactámico ${ }^{9}$. La producción de beta-lactamasas es el mecanismo más frecuente de resistencia antibiótica. Existen continuas mutaciones que producen expresión de beta-lactamasas de espectro extendido (BLEE), manifestándose como resistencia a cefalosporinas de $3^{\mathrm{a}}$ generación (ceftriaxona). Para combatir esta resistencia se utiliza un inhibidor enzimático que tiene mayor afinidad a la enzima e impide la destrucción del antimicrobiano y de esta manera permite su acción (clavulanato y sulbactam). Las BLEE se asocian a co-resistencia con aminoglicósidos y cotrimoxazol, dada la frecuencia de transferencia en el mismo plasmidio.

\section{2) Modificación del sitio activo}

La modificación de un aminoácido genera un blanco diferente y así disminuye la afinidad de unión por el antimicrobiano.

- Modificación de PBP: El PBP (penicillinbinding-protein) es un complejo enzimático que permite la síntesis del peptidoglicano, un compuesto de la pared celular en bacterias, principalmente en Gram positivas, si se produce mutación del sitio de unión al antimicrobiano como los beta-lactámicos, éstos no pueden actuar y se genera resistencia a ellos.

- Modificación ribosomal: Los genes erm A y erm $B$ producen modificación del sitio activo del ribosoma, mediante metilación. Este mecanismo es importante en la resistencia a macrólidos en $S$. pneumoniae y $S$. pyogenes ${ }^{10}$.

\section{3) Disminución de la permeabilidad de la pared celular al ingreso del antimicrobiano}

Cambios en el diámetro y/o número de porinas pueden bloquear el ingreso del antimicrobiano a la bacteria.
- Porinas: Existe disminución de la expresión de porinas (downregulation) lo que disminuye la susceptibilidad a betalactámicos y fluorquinolonas en Pseudomonas ${ }^{11}$.

\section{4) Bombas de eflujo}

Transporta al antimicrobiano hacia el exterior de la célula sin modificaciones, pero sin acción antimicrobiana. Existen bombas de eflujos multidrogas en la pared bacteriana que permiten la expulsión de drogas como los antimicrobianos. Los genes involucrados son MefA (Streptococcus pneumoniae), NorA (Staphylococcus aureus) y Mex (Pseudomonas aeruginosa). Estos genes explican la resistencia a macrólidos en estos patógenos $^{12}$ y a fluoroquinolonas. Para combatir este tipo de resistencia se encuentran en estudio la asociación de inhibidores de bombas de eflujo junto con el antimicrobiano ${ }^{13}$.

\section{TRANSFERENCIA HORIZONTAL DE GENES}

La transferencia horizontal de genes es el traspaso de información genética entre bacterias, proceso diferente a la replicación. Permite variabilidad genética y evolución bacteriana, generando la capacidad de adaptarse a las variaciones del medio. Las bacterias utilizan diversas vías para transferir información genética: conjugación, transducción y transformación (Figura 2). Estos mecanismos son el mayor determinante en la evolución bacteriana, diseminando genes de virulencia ${ }^{14}$. Es una transmisión dinámica que genera plasticidad en los genomas, dando propiedades patogénicas a muchos agentes infecciosos, previamente inocuos ${ }^{15}$.

\section{Conjugación}

Proceso mediado por plasmidios, elementos conjugativos, que tienen la propiedad de transferirse de una célula a otra gracias a un contacto cercano entre ambas células mediante un poro de conjugación o pili sexual. Los plasmidios son elementos genéticos móviles, de forma circular, poseen replicación propia, es decir, independiente de la duplicación bacteriana. Dentro de su información poseen casettes génicos que codifican para resistencia bacteriana. 


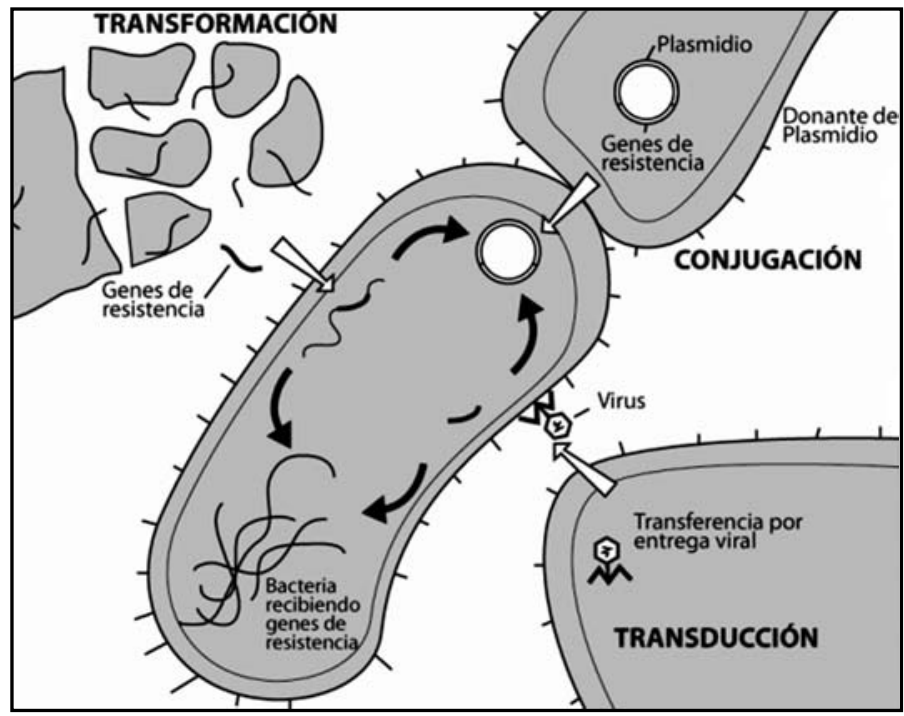

Figura 2. Transferencia horizontal de genes. Se adquiere material genético por conjugación, transducción y transformación. Además se producen deleciones y mutaciones genéticas, que optimizan los procesos bacterianos ${ }^{16}$.

\section{Transducción}

Es la transferencia de material genético de una bacteria a otra mediante un virus que infecta bacterias (bacteriófago). Este virus puede integrarse en el genoma bacteriano y al transferirse a otra célula puede llevar parte del genoma de esta bacteria y así trasferir genes, entre ellos genes de resistencia antimicrobiana.

\section{Transformación}

Es la captura de ADN extracelular del medio, que puede integrarse en el genoma y expresarse.

\section{BACTERIAS DE IMPORTANCIA EN ORL}

Las infecciones del tracto respiratorio representan la causa más frecuente de consulta médica y de prescripción antibiótica. El tracto respiratorio superior es más susceptible de infecciones bacterianas en individuos con cuadros alérgicos, infecciones virales, efectos del tabaquismo y la contaminación ambiental. Streptococcus pneumoniae, Haemophilus influenzae y Moraxella catarrhalis constituyen los principales agentes patógenos del tracto respiratorio que se adquieren en la comunidad ${ }^{17}$. Durante los últimos 20 años se ha observado un aumento de la resistencia antibiótica en muchas bacterias patógenas respiratorias, con modesto desarrollo de nuevos antimicrobianos para combatir este problema. La producción de beta-lactamasa es uno de los mecanismos principales de resistencia de estos organismos, otros mecanismos incluyen impermeabilidad a la membrana, bombas de eflujo, alteración del ribosoma ${ }^{18}$. Estudios en OMA muestran una resistencia a $S$. pneumoniae y $H$. influenzae, asociado a una disminución de la respuesta bacteriológica del tratamiento antimicrobiano, con impacto en la respuesta clínica. Esto sucede por el uso masivo y frecuente de Ios antimicrobianos, que selecciona cepas resistentes que luego son portadas en la cavidad nasofaríngea de niños y transmitidas a sus familiares y compañeros de escuela, creando un círculo vicioso, aumentando aún más la resistencia y disminuyendo la respuesta clínica, incrementando nuevamente el uso de antimicrobianos $^{19}$. Se ha observado que el tejido adenoideo de individuos sanos generalmente es colonizado por bacterias aeróbicas y anaeróbicas que interfieren el desarrollo de patógenos, esta protección no sucede en pacientes con infecciones recurrentes del tracto respiratorio. En consecuencia, es importante mantener los beneficios de la microbiota normal 
evitando la exposición innecesaria a los antimicrobianos y así prevenir la colonización de adenoides por potenciales patógenos ${ }^{20}$.

Algunas de las bacterias que dan grandes problemas de resistencia antimicrobiana en infecciones respiratorias son: Streptococcus pneumoniae, Haemophilus influenzae, Streptococcus pyogenes, Pseudomonas aeruginosa.

\section{Streptococcus pneumoniae}

Se describe resistencia a penicilina en 20\%-30\% y a cefotaximo en $15 \%$. Existen diferencias según grupo etario: la resistencia de alto nivel a penicilina es de $30 \%$ en niños menores de 5 años de edad y notablemente inferior (12\%-13\%) en niños sobre 5 años. Con cefotaximo se observa la misma diferencia siendo menos notable. Esta alta resistencia se puede atribuir al uso masivo de antimicrobianos en niños, el intercambio de microorganismos en los jardines infantiles, y otras situaciones que lleven a diseminación de las cepas ${ }^{21}$.

Los mecanismos de resistencia de $S$. pneumoniae a beta-lactámicos, son variados, siendo el más importante la alteración de PBP (penicillin binding protein) ${ }^{22}$, proteínas de síntesis de la pared celular (1a, 1b, 2a, 2b, 2x). Dentro de este grupo, 1a y $2 b$ son de alto nivel de resistencia a la penicilina y 1 a y $2 x$ para cefalosporinas de tercera generación (cefotaxima).

Se produce un interesante fenómeno de transferencia genética entre Streptococcus del grupo viridans con $S$. pneumoniae en la faringe al existir selección por el uso de antimicrobianos (especialmente ampicilina y amoxicilina).

La resistencia a macrólidos se describe en $25 \%$, los mecanismos de resistencia a macrólidos más frecuentes en $S$. pneumoniae son la metilación del ribosoma mediante el gen erm $B$ en $58 \%$ y sistemas de bombas de eflujo mediante el gen mef $A$ en $30 \%$ aproximadamente, existen cepas con ambos genes de resistencia, en $12 \%{ }^{23}$.

La resistencia a fluoroquinolonas respiratorias como levofloxacino y moxifloxacino es menos del $1 \%$. Los mecanismos de resistencia a fluororquinolonas son por mutación de enzimas como girasa y topoisomerasa, sitios donde actúa el antimicrobiano, y sistemas de eflujo, identificadas en el gen pmrA. Afortunadamente, las nuevas fluoroquinolonas no presentan altos grados de resistencia como el ciprofloxacino y disminuyen el riesgo de la emergencia de cepas resistentes ${ }^{24}$.

\section{Haemophylus influenzae}

La prevalencia ha disminuido en forma dramática, especialmente el serotipo b, debido a la incorporación de la vacuna en 1996 en el plan nacional de inmunizaciones. En el estudio LASER se han identificado cepas productoras de beta-lactamasa en Latinoamérica, desde 15\% (Brasil) -25\% (Panamá); Chile muestra una prevalencia de $18 \%$ de este mecanismo. La producción de beta-lactamasa es el mecanismo más importante de resistencia a las aminopenicilinas, presentando variación según la zona geográfica. La susceptibilidad antibiótica es superior al 95\% cuando se utilizan inhibidores de beta-lactamasa como es clavulanato o sulbactam, asociado al beta-lactámico ${ }^{25}$.

\section{Moraxella catarrhalis}

Existe alta prevalencia de producción de betalactamasa, cercana al $100 \%$, en muchos países a nivel mundial, lo que le confiere resistencia a amoxicilina en $80 \%-100 \%$. Otras resistencias antimicrobianas son: $5 \%$ a macrólidos, $14 \%$ para amoxicilina/ac. clavulánico, 20\% cefuroximo y $30 \%$ cotrimoxazol. Con respecto a fluoroquinolonas, se observó $100 \%$ de cepas sensibles.

\section{Streptococcus pyogenes}

Existen Streptococcus B-hemolíticos A, B, C, F, G y no agrupables. Algunos son estreptococos «piogénicos» con una variedad de mecanismos efectivos de virulencia que se traducen en su patogenicidad, mientras otros habitualmente forman parte de la microbiota comensal, aunque pueden aislarse en abscesos (Streptococcus milleri y Streptococcus anginosus) ${ }^{26}$.

La sensibilidad a penicilina no ha tenido cambios importantes, sin embargo, puede existir falla en la erradicación bacteriológica del $S$. pyogenes de la faringe, cercanas al 30\%, situación indispensable para la prevención de la enfermedad reumática.

Los macrólidos, muestran eficacia similar a la penicilina en pacientes con infecciones por $S$. 
pyogenes. Su uso indiscriminado ha generado la aparición de cepas resistentes, la resistencia a eritromicina es de $0,5 \%$ a $60 \%$, en Chile se ha descrito resistencia en $7,2 \%$.

Dentro de los mecanismos de resistencia descritos para los macrólidos destaca como más importante la alteración en el ribosoma, mediante una enzima metilasa dependiente del gen erm, de origen plasmidial 0 cromosomal ${ }^{27}$. El mecanismo de resistencia de eflujo se ubica en el gen $m e f A$, corresponde a cepas resistentes a eritromicina, pero susceptibles a clindamicina.

\section{Pseudomonas aureginosa}

Pseudomonas es responsable de muchas infecciones severas como otitis externa difusa, otitis externa maligna, OMC y pericondritis. Dentro de los beta-lactámicos, los únicos con acción antipseudomona son ceftazidima, cefoperazona y cefepime, la susceptibilidad a ceftazidima se mantiene en más del $90 \%$, sin embargo la resistencia a ciprofloxacino ha aumentado ${ }^{28}$. La resistencia antimicrobiana es una causa importante en la falla del tratamiento. Los mecanismos de resistencia se expresan por genes para bombas de eflujo, mutaciones que modifican el sitio de acción de los antimicrobianos, producción de $\beta$ lactamasas y disminución de la permeabilidad al antibiótico. La resistencia a fluoroquinolonas es de $25 \%$ y se explica por sistemas de eflujo. Este problema se soluciona aumentando las concentraciones en el sitio de acción para la erradicación efectiva y la prevención de cepas resistentes. La disminución de la expresión de porinas a nivel de la membrana externa, genera resistencia a imipenem y meropenem ${ }^{29}$.

\section{DISCUSIÓN}

El tratamiento antibiótico se realiza de manera empírica en la práctica clínica otorrinolaringológica, sin embargo el fracaso a los tratamientos obliga a identificar las cepas bacterianas y su patrón de resistencia antibiótica.

La elección de un tratamiento antimicrobiano para otitis y sinusitis se ha vuelto más compleja debido al incremento en las tasas de resistencia antimicrobiana en los patógenos respiratorios. Entre las opciones terapéuticas siguen destacando beta-lactámicos como amoxicilina, amoxicilinaclavulánico; macrólidos y fluoroquinolonas. Las cefalosporinas orales como cefuroximo son una buena alternativa para casos complejos.

Asociado a la resistencia antimicrobiana existen pacientes más susceptibles a las infecciones bacterianas, debido a la disminución o ineficiencia de la respuesta inmune, es el caso de pacientes diabéticos, inmunosuprimidos (VIH, cáncer), drogas inmunomoduladoras (trasplantes), edades extremas, entre otras, lo que genera un problema mayor.

El control de la prescripción de antimicrobianos permite cambiar patrones de resistencia, es fundamental mantener indicaciones correctas de acuerdo al diagnóstico planteado, seleccionando un tratamiento adecuado. Esta estrategia puede disminuir el problema de resistencia.

Conocer los mecanismos de resistencia permite investigar nuevos blancos de acción para blo-

Tabla 1. Mecanismos de resistencia antimicrobiana en los principales patógenos respiratorios ${ }^{30}$

\begin{tabular}{|lll|}
\hline Patógeno respiratorio & Antimicrobiano & Mecanismo de resistencia \\
\hline S. pneumoniae & Betalactámicos & Mutación de PBP \\
& Macrólidos & Metilación del ribosoma (genes erm) \\
& & Bombas de eflujo (genes mefA) \\
H. influenzae y M. catarrhalis & Betalactámicos & Hidrólisis enzimática por betalactamasas \\
S. pyogenes & Betalactámicos & Sin resistencia \\
& Macrólidos & Metilación del ribosoma (genes erm) \\
& & Bombas de eflujo (genes mefA) \\
\hline
\end{tabular}


quear estos mecanismos, y así permitir la acción antimicrobiana deseada, como sucede con inhibidores de beta-lactamasas. En el futuro, pueden ser importantes los inhibidores de bombas de eflujo, como ya se está estudiando para cepas resistentes en Pseudomonas, importante en el manejo de otitis externa maligna.

\section{Agradecimientos}

Sabina Lorca M, Neurobiology, Houston, Texas. USA Sebastián Aravena 0, diseñador gráfico.

\section{BIBLIOGRAFÍA}

1. Nicolau D. Clinical and economic implications of antimicrobial resistance for the management of community-acquired respiratory tract infections. J Antimicrob Chemother 2002; 50 Suppl S1: 61-70.

2. Martínez JL, Baquero F, Andersson DI. Predicting antibiotic resistance. Nat Rev Microbiol 2007; 5(12): 958-65.

3. VIRGIN HW. In vivo veritas: pathogenesis of infection as it actually happens. Nat Immunol 2007; 8(11): 1143-7.

4. Stecher B, HaRdt WD. The role of microbiota in infectious disease. Trends Microbiol 2008; 16(3): 107-14. Epub 2008 Feb 14.

5. JARVIS WR. The epidemiology of colonization. Infect Control Hosp Epidemiol 1996; 17(1): 4752.

6. Jarvis WR. The epidemiology of colonization. Infect Control Hosp Epidemiol 1996; 17(1): 47-52.

7. Groisman EA, Casadesús J. The origin and evolution of human pathogens. Mol Microbiol 2005; 56(1): 1-7.

8. Valenzuela, M Teresa, Prat, M Soledad, Santolaya, M Elena et al. Starting a national surveillance network of antibiotic resistance classified by clinical síndromes. Rev Chil Infect (2003); 20 (2): 119-25.

9. Viswanatha T, Marrone L, Goodfellow V, DMITRIENKo Gl. Assays for beta-lactamase activity and inhibition. Methods Mol Med 2008; 142: 239-60.

10. Wierzbowski AK, Hoban DJ, Hisanaga T, Decorby M, Zhanel GG. The Use of Macrolides in
Treatment of Upper Respiratory Tract Infections. Curr Infect Dis Rep 2005; 7(3): 17584.

11. Driscoll JA, Brody SL, Kollef MH. The epidemiology, pathogenesis and treatment of Pseudomonas aeruginosa infections. Drugs 2007; 67(3): 351-68.

12. Gотон N. Antibiotic resistance caused by membrane impermeability and multidrug efflux systems. Nippon Rinsho 2001; 59(4): 712-8.

13. Zhanel GG, Hoban DJ, Schurek K, Karlowsky JA. Role of efflux mechanisms on fluoroquinolone resistance in Streptococcus pneumoniae and Pseudomonas aeruginosa. Int I Antimicrob Agents 2004; 24(6): 529-35.

14. BG Kelly A, A Vespermann, DJ Bolton. The role of horizontal gene transfer in the evolution of selected foodborne bacterial pathogens. Food Chem Toxicol 2008; Feb 14.

15. Ahmed N, Dobrindt U, Hacker J, Hasnain SE. Genomic fluidity and pathogenic bacteria: applications in diagnostics, epidemiology and intervention. Nat Rev Microbiol 2008; 6(5): 387-94.

16. BG Kelly A, A. Vespermann, DJ Bolton. The role of horizontal gene transfer in the evolution of selected foodborne bacterial pathogens. Food Chem Toxicol 2008; Feb 14.

17. BRook I. Effects of antimicrobial therapy on the microbial flora of the adenoids. J Antimicrob Chemother 2003; 51(6): 1331-7.

18. Cappelletty D. Microbiology of bacterial respiratory infections. Pediatr Infect Dis $J$ 1998; 17(8 Suppl): S55-61.

19. Dagan R. Treatment of acute otitis media challenges in the era of antibiotic resistance. Vaccine 2000; 19 Suppl 1: S9-S16.

20. BRook I. Effects of antimicrobial therapy on the microbial flora of the adenoids. $J$ Antimicrob Chemother 2003; 51(6): 1331-7.

21. M. Pinto. Antimicrobial agents resistance in Chile nowdays. Rev Chil Infect (2002); 19 (Supl 3): S213-S218.

22. ChIOU CC, HseiH KS. Pneumococcal infection in children: rational antibiotic choice for drugresistant Streptococcus pneumoniae. Acta Paediatr Taiwan 2003; 44(2): 67-74.

23. Felmingham D, Cantón R, Jenkins SG. Regional trends in beta-lactam, macrolide, fluoroqui- 
nolone and telithromycin resistance among Streptococcus pneumoniae isolates 20012004. J Infect 2007; 55(2): 111-8. Epub 2007 Jun 12.

24. Zhanel GG, Hoban DJ, Schurek K, Karlowsky JA. Role of efflux mechanisms on fluoroquinolone resistance in Streptococcus pneumoniae and Pseudomonas aeruginosa. Int $J$ Antimicrob Agents 2004; 24(6): 529-35.

25. Alpuche C, Garau J, Lim V. Global and local variations in antimicrobial susceptibilities and resistance development in the major respiratory pathogens. Int $J$ Antimicrob Agents 2007; 30 Suppl 2: S135-8. Epub 2007 Oct 22.

26. Rossanna Camponovo. Antimicrobial resistance in Streptococcus pyogenes. Rev Chil Infectol v.19 supl. 2 Santiago 2002.
27. Claudia Vinagre, Marcela Cifuentes, Francisca Valdivieso, Alicia OJeda, Valeria Prado. Emergence of macrolide resistant Streptococcus pyogenes strains. Rev Méd Chile v.127 n.12 Santiago dic. 1999.

28. ELIES W. Current therapeutical management, new antibiotics and treatment of Pseudomonas aeruginosa in bacterial ENT-infections. Laryngorhinootologie 2002; 81(1): 40-5.

29. Farra A, Islam S, Strålforos A, Sörberg M, WRETLIND B. Role of outer membrane protein OprD and penicillin-binding proteins in resistance of Pseudomonas aeruginosa to imipenem and meropenem. Int $J$ Antimicrob Agents 2008; 31(5): 427-33.

30. Baquero y col. Clin Microb Infect 1998; 4 ( supl 2): $19-26$. 